\section{Cureus}

Received 02/19/2019

Review began 04/04/2019

Review ended 05/13/2019

Published 05/21/2019

\section{(c) Copyright 2019}

Martinez-Cordero et al. This is an open access article distributed under the terms of the Creative Commons Attribution License CC-BY 3.0., which permits unrestricted use, distribution, and reproduction in any medium, provided the original author and source are credited.

\title{
Myelomastocytic Blast Cell Crisis in Resistant Tyrosine Kinase Inhibitor Chronic Myelogenous Leukemia: Case Report and Review of Literature
}

Humberto Martinez-Cordero ${ }^{1}$, Bonell Patiño-Escobar ${ }^{2}$, Leonardo J. Enciso ${ }^{1}$, Diana M. Otero ${ }^{1}$ , Paola Spirko ${ }^{1}$

1. Hematology, National Cancer Institute, Bogotá, COL 2. Hematology, San Jose Hospital - University Foundation of Health Sciences, Bogotá, COL

$\square$ Corresponding author: Bonell Patiño-Escobar, bonell32@hotmail.com Disclosures can be found in Additional Information at the end of the article

\section{Abstract}

We present the clinical case of a 29-year-old male with a diagnosis of chronic myeloid leukemia (CML) in high-risk chronic phase since February 2010. He started treatment with imatinib at a dose of $400 \mathrm{mg}$ obtaining a hematologic response early but without reaching a cytogenetic response in month 18 . Then, dasatinib was prescribed. The BCR-ABL transcription level of 58\% was documented. It was decided to start treatment with nilotinib but in March 2017 we diagnosed a progression to blast crisis (BC) of myeloid origin with a bone marrow study that documented $72 \%$ of blasts with normal karyotype, also very striking, the concomitant skin infiltration, bone lesions of lytic type and hypercalcemia that required the use of zoledronic acid as an emergency. At the end of chemotherapy induction with $7+3$ (seven days of cytarabine and three days of idarubicin) chemotherapy associated with bosutinib for 14 days and after several infectious complications, we documented a percentage of blasts by flow cytometry of $29 \%$ in the bone marrow and the existence of $46 \%$ of cells with basophilic characteristics versus mast cells. A basophilic transformation was suspected versus aggressive systemic mastocytosis with a clonal, nonmastocytic hematological disorder. Levels of serum tryptase and mutation D816V C KIT were requested, which were not possible to perform. Treatment with CLAG-M was proposed, however, the patient died early with hyperleukocytosis and severe thrombocytopenia with central nervous system bleeding.

Categories: Internal Medicine, Pathology, Oncology

Keywords: mast cell leukemia, chronic myeloid leukemia, myeloid blast crisis, leukemia, hypercalcemia, central nervous system (cns) complications, mast cells, intracranial bleed

\section{Introduction}

Chronic myeloid leukemia is a heterogeneous disease. Clinical course is categorized in three phases (Chronic, accelerated and blast crisis) with specific diagnostic criteria. Despite the definition of the phases, clinical presentation might be different, regarding the prognostic score, different response to the tyrosine kinase inhibitors and self features of each patient, furthermore of genetic variations that confer resistance to certain medications.

Lack of compliance of therapeutic regimen with tyrosine kinase inhibitors may lead to a blast crisis progression with a very bad prognosis. Nevertheless, a blast crisis may be a devastating scenario in a disease that has been considered cured with the new strategy approach.

\section{How to cite this article}

Martinez-Cordero H, Patiño-Escobar B, Enciso L J, et al. (May 21, 2019) Myelomastocytic Blast Cell Crisis in Resistant Tyrosine Kinase Inhibitor Chronic Myelogenous Leukemia: Case Report and Review of Literature. Cureus 11(5): e4703. DOI 10.7759/cureus.4703 
Blast cells crisis in chronic myeloid leukemia comprises, in most cases, the myeloid or lymphoid phenotype. Myelomastocytic blast cell crisis is rare and the prognosis is not clearly defined. The objective of this case report is to show the clinical behavior of a patient treated at a reference hemato-oncology center in Colombia. This work has been published as an abstract (https://www.clinical-lymphoma-myeloma-leukemia.com/article/S2152-2650(18)308462/fulltext).

\section{Case Presentation}

We present the clinical case of a 29-year-old male patient treated at the Instituto Nacional de Cancerología of Colombia with a diagnosis of chronic myelogenous leukemia (CML) in highrisk chronic phase since February 2010. He started treatment with imatinib at a dose of $400 \mathrm{mg}$, obtaining a hematological response in the second month but not achieving a cytogenetic response in the 18th month. At that time, the patient continued treatment in another institution. It was possible to elucidate that the patient had a change of his treatment to dasatinib in March 2013 with the previous verification of the lack of cytogenetic response documenting a level of BCR-ABL transcription of $6.3 \%$, period after which the patient, unfortunately, lasted eight months without treatment due to assurance problems. In September 2016, a BCR-ABL transcription level of 58\% was documented, without a real knowledge about how much time he had taken dasatinib continuously at the moment of BCR/ABL evaluation; then, nilotinib treatment was begun.

The patient was readmitted to our institution in March 2017 and we diagnosed a progression to blast crisis of myeloid origin with a bone marrow study that documented $72 \%$ of blasts with karyotype without the growth of metaphases, being also very striking, the concomitant infiltrative cutaneous involvement, bone lesions of lytic type and hypercalcemia that required the use of zoledronic acid as an oncological emergency (Figure 1). 


\section{Cureus}

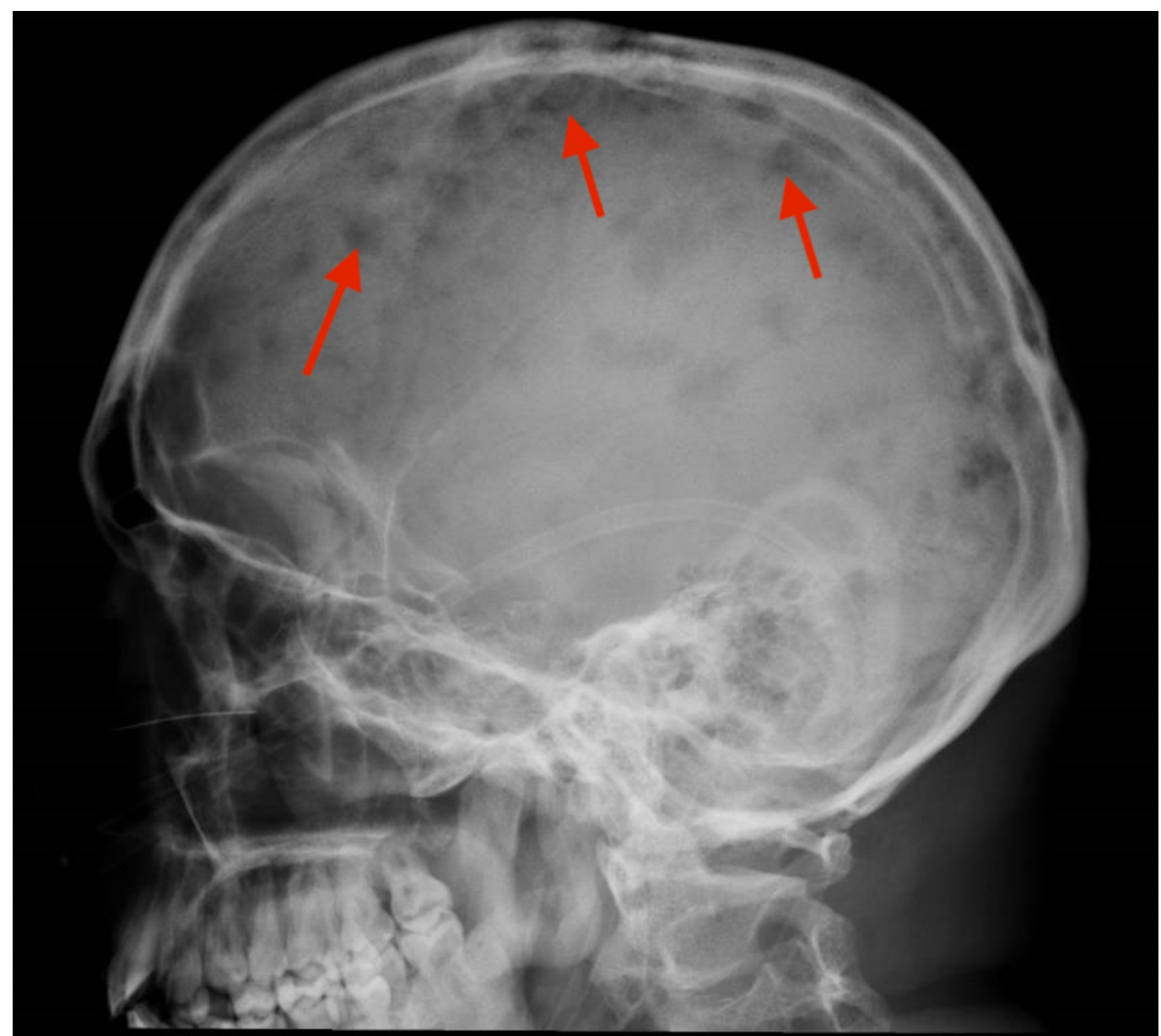

FIGURE 1: Multiple cranial lytic lesions.

At the end of the induction with $7+3$ (seven days of cytarabine and three days of idarubicin) chemotherapy associated with bosutinib for 14 days and after several infectious complications, including invasive fungal infection and bacteremia due to Enterococcus faecium, as well as symptomatic hypocalcemia because of bisphosphonates, it was documented a percentage of blasts by flow cytometry of $29 \%$ in bone marrow and the existence of $46 \%$ of cells with basophilic versus mast cell characteristics on day 28 at the end of induction (Figures 2, 3).

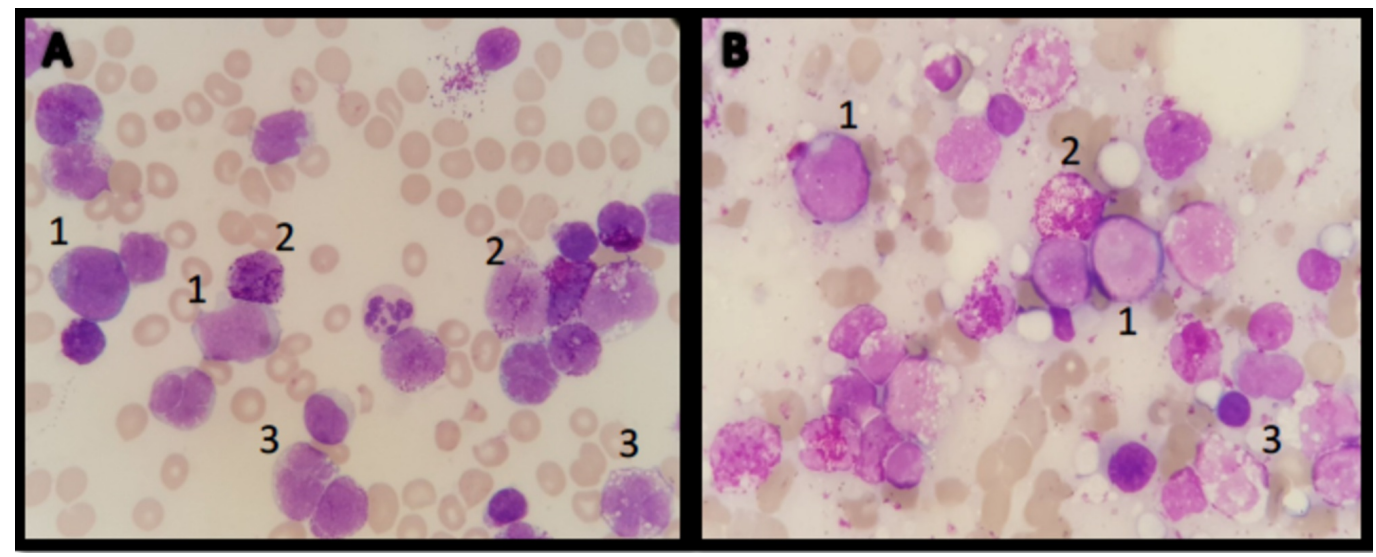

FIGURE 2: Cytomorphological examination, Wright 100x.

(A) Peripheral blood and (B) bone marrow aspirate: 1. Blasts. 2. Multilobulated cells with abundant 


\section{Cureus}

metachromatic granules and 3. Cells with lax chromatin, multi-loculated, basophilic hypogranular cytoplasm and/or with vacuoles.
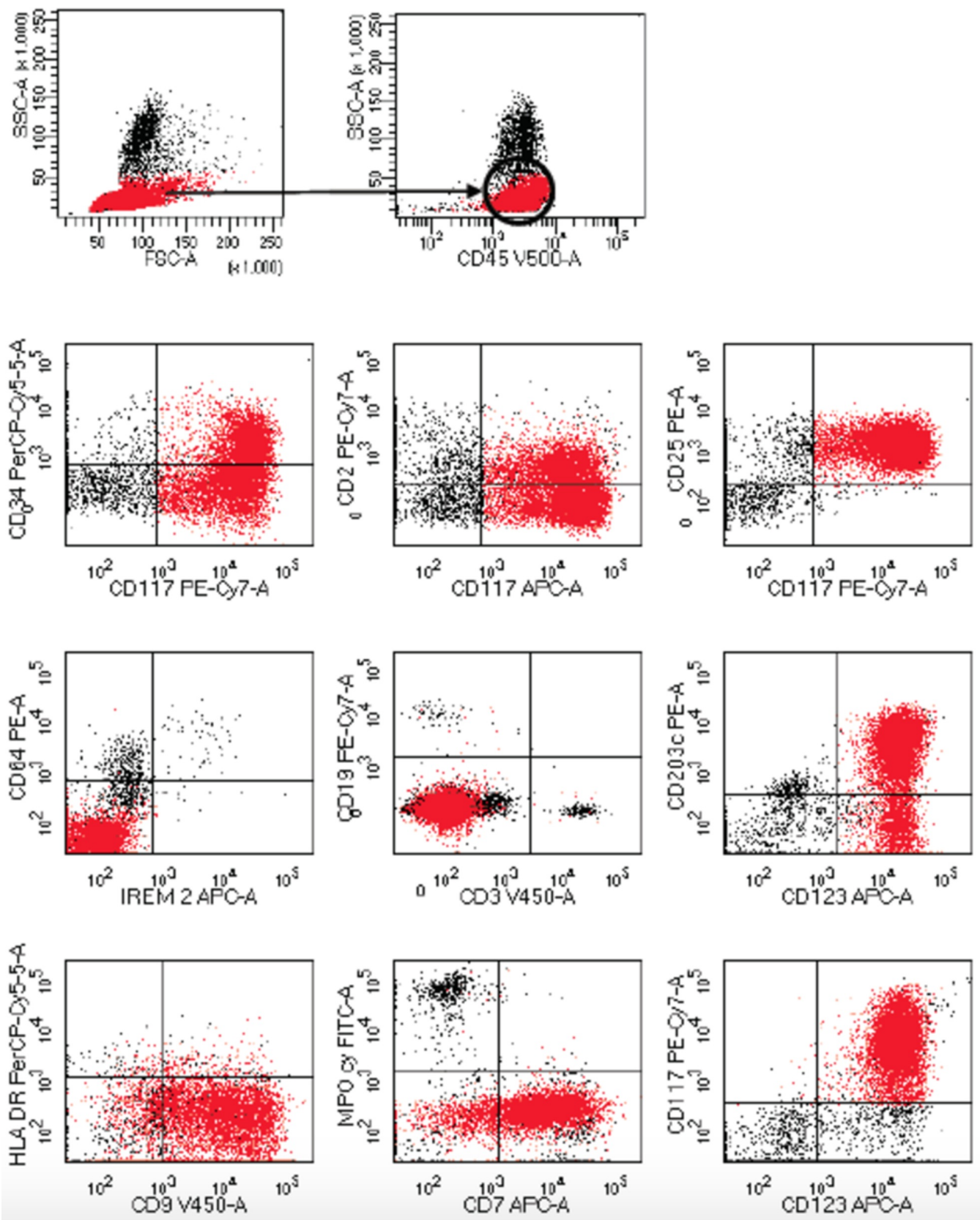

\section{FIGURE 3: The flow cytometry study in bone marrow aspiration.}

It reveals a population of large size and complexity (red events) with intermediate CD45 and positivity for CD117, CD25, CD123 and CD9 heterogeneous with partial expression of CD34, CD2, CD203c and CD7. Note the negativity for MPO, CD64, IREM2, CD19, CD3s and HLA DR. This immunological profile has similarity between basophils vs mast cells, being more likely a mastocytic differentiation due to the strong expression of CD117, CD123 and CD25, interpreting these results as a chronic myeloid leukemia (CML) in blast crisis probably with mast cell differentiation. 


\section{Cureus}

A basophilic transformation was suspected versus aggressive systemic mastocytosis with a clonal, non-mastocytic hematological disorder (Figures 2, 3). Levels of serum tryptase and mutation D816V C KIT were requested, which were not reported. Treatment with CLAG-M (Cladribine, Cytarabine [Arabinosylcytosine-araC], granulocyte colony-stimulating factor [G$\mathrm{CSF}$ ], Mitoxantrone) was proposed, however, the patient died early in hyperleukocytosis and severe thrombocytopenia with central nervous system bleeding (Figure 4).

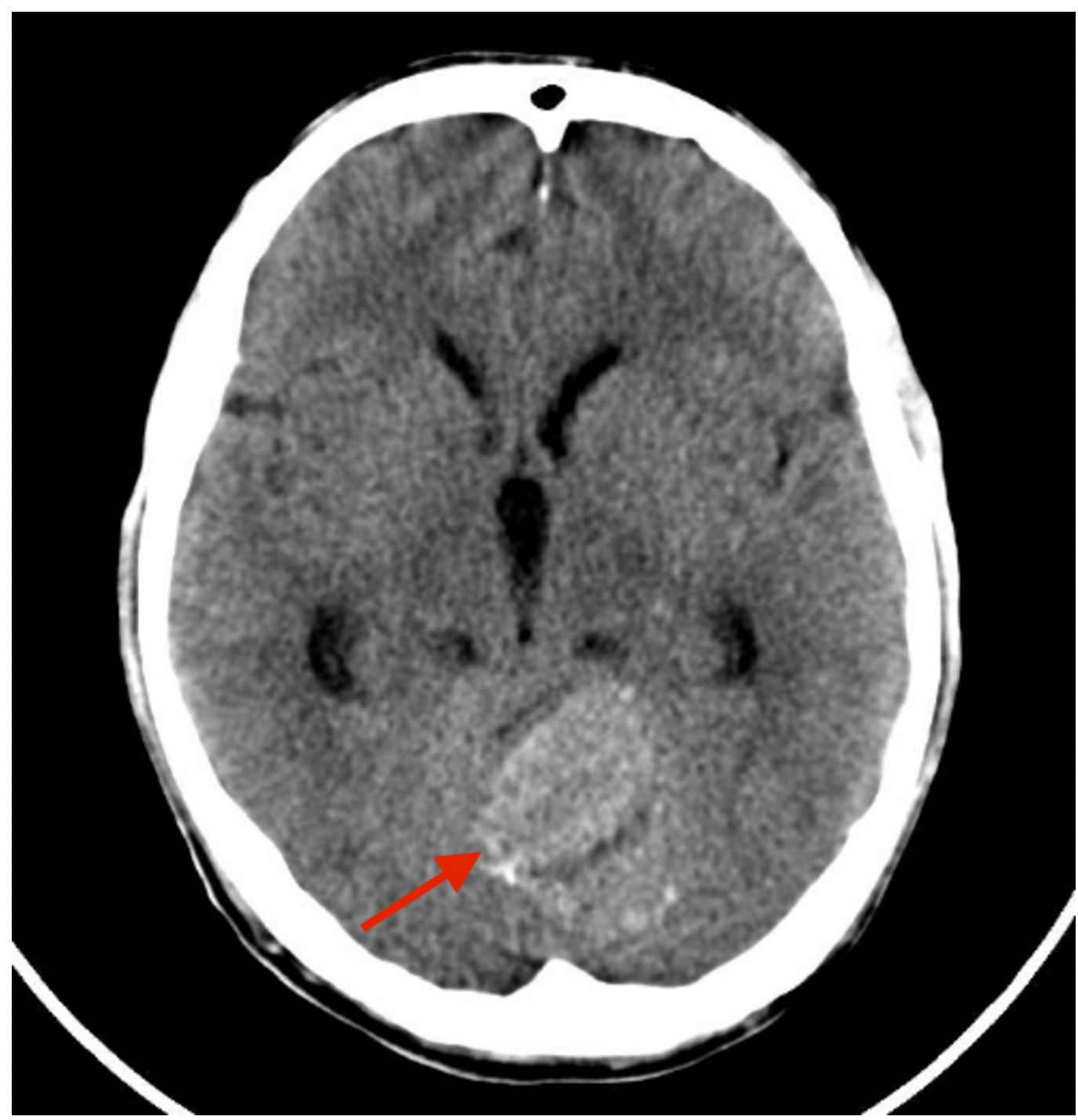

FIGURE 4: Computed tomography showing bleeding of the central nervous system.

\section{Discussion}

The CML has a three-phase behavior in which the clinical presentation of each phase, prognosis, and treatment are substantially different; the phases are: chronic phase (FC), accelerated phase (AF) and blast crisis (BC) [1]. In the past, virtually all patients progressed to $\mathrm{BC}$ with a median survival so short that they were usually measured in months. Despite the advent of current tyrosine kinase inhibitors (TKI) and the use of allogeneic hematopoietic stem cell transplantation, there is no significant improvement of overall survival [2]. The treatment of the disease in this phase is a challenge due to the high rates of therapeutic failure and mortality. The therapeutic schemes currently used are TKI associated with high-intensity 
systemic chemotherapy and allogeneic stem cell transplantation [2-4]. The choice of chemotherapy depends on the cellular phenotype of the acute leukemic transformation. The most common phenotype of $\mathrm{BC}$ is the myeloid phenotype comprising approximately two-thirds of the cases, followed by the lymphoid, megakaryocytic, erythroid, basophilic, and rarely monocytic and eosinophilic phenotype [5]. The BC with mastocytic differentiation is an absolutely rare entity and only two cases have been reported in the literature around the world $[6,7]$. The diagnosis is usually very difficult due to similar morphological, phenotypical and functional characteristics between basophilic blast crisis and mast cells, but the latter originate from a different precursor in the bone marrow. In addition, classifying the disease clinically is a challenge due to the characteristics shared with systemic mastocytosis. In our case, we did not have available tryptase levels or D816V C KIT mutation [7-10].

We present a patient diagnosed with CML, with a lack of compliance and/or resistant to the three tyrosine kinase inhibitors available for initial treatment, who progresses to blast cell crisis and in whose tests we demonstrate the existence of a population with mast cell differentiation that was difficult to differentiate from the blast cell population. After a rescue plan using chemotherapy for myeloid blast crisis associated with bosutinib, the patient died of central nervous system bleeding, and it was impossible to go ahead with a scheme based on cladribine as a second rescue. We have previously reported on the possibility of central nervous system bleeding in patients at an advanced stage of the disease [11].

\section{Conclusions}

There are no guidelines on treatment in this scenario due to the rarity of this entity and it is assumed that patients with this clinical presentation have a high rate of mortality after they are diagnosed. Records of unusual BC presentations are necessary to define treatment strategies even if they are supported in retrospective studies.

\section{Additional Information}

\section{Disclosures}

Human subjects: Consent was obtained by all participants in this study. Instituto Nacional de Cancerología issued approval not applicable. Regarding the descriptive and retrospective cases where it has not been possible to obtain a patient's permission (in case of death or loss of contact), if a patient's confidentiality has been preserved and when the number of patients is less than ten, the ethics committee approves without an ethics meeting applying the manuscript as institutional statement. Conflicts of interest: In compliance with the ICMJE uniform disclosure form, all authors declare the following: Payment/services info: All authors have declared that no financial support was received from any organization for the submitted work. Financial relationships: All authors have declared that they have no financial relationships at present or within the previous three years with any organizations that might have an interest in the submitted work. Other relationships: All authors have declared that there are no other relationships or activities that could appear to have influenced the submitted work.

\section{Acknowledgements}

We owe such a strong acknowledgement to the Pathology and Flow Cytometry Department of Instituto Nacional de Cancerologia for their restless work for well-being of our patients, and for their big collaboration in this manuscript.

\section{References}

1. Arber D, Orazi A, Hasserjian R, et al.: The 2016 revision to the World Health Organization 
classification of myeloid neoplasms and acute leukemia. Blood. 2016, 127:2391-2405. 10.1182/blood-2016-03-643544

2. Hehlmann R, Saussele S: Treatment of chronic myeloid leukemia in blast crisis . Haematologica. 2008, 93:1765-1769. 10.3324/haematol.2008.001214

3. Gambacorti C, Cortes J, Kim DW, et al.: Efficacy and safety of dasatinib in patients with chronic myeloid leukemia in blast phase whose disease is resistant or intolerant to imatinib: 2-year follow-up data from the START Program. Blood. 2007, 110:472.

4. Cortes J, Kim DW, Raffoux E, et al.: Efficacy and safety of dasatinib in imatinib-resistant or intolerant patients with chronic myeloid leukemia in blast phase. Leukemia. 2008, 22:21762183. 10.1038/leu.2008.221

5. Tsunemine H, Arima H, Itoh K, Sakane-Ishikawa E, Akasaka H, Kodaka T, Takahashi T: Monocytic crisis of chronic myeloid leukemia in the era of tyrosine kinase inhibitor . J Clin Exp Hematop. 2013, 53:227-233. 10.3960/jslrt.53.227

6. Soler J, O’Brien M, de Castro JT, Miguel JF, Kearney L, Goldman JM, Catovsky D: Blast crisis of chronic granulocytic leukemia with mast cell and basophilic precursors. Am J Clin Pathol. 1985, 83:254-259. 10.1093/ajcp/83.2.254

7. Vigil CE, Wang SA, Cortes JE, et al.: Dasatinib-responsive mast cell neoplasms as initial presentation of chronic myelogenous leukemia in blast phase. J Clin Oncol. 2011, 29:514-516. 10.1200/JCO.2010.34.1610

8. Georgin-Lavialle S, Lhermitte L, Dubreuil P, Chandesris MO, Hermine O, Damaj G: Mast cell leukemia. Blood. 2013, 121:1285-1295. 10.1182/blood-2012-07-442400

9. Lu DY, Gau JP, Hong YC, et al.: Mast cell leukemia: an extremely rare disease . J Chin Med Assoc. 2014, 77:446-449. 10.1016/j.jcma.2014.05.004

10. Cehreli C, Alacacioglu I, Piskin O, et al.: Mast cell leukemia associated with undefined morphology and chronic basophilic leukemia. BMC Hematol. 2014, 14:17. 10.1186/2052-183914-17

11. Bautista-Toloza L, Martínez H, Bonell-Patiño O: Intraparenchymal haematoma of the central nervous system associated with Dasatinib in the treatment of chronic myeloid leukaemia in accelerated phase. Presentation of two cases and review of literature. Rev Colomb Cancerol. 2018, 22:151-156. 10.1016/j.rccan.2017.10.002 